\title{
OPTIMALISASI BAHAN PEMBELAJARAN IPS BERBASIS TEKNOLOGI INFORMASI DI MGMP IPS JAKARTA TIMUR
}

\author{
Budiaman $^{1}$, Rusmono ${ }^{2}$, Nandi Kurniawan ${ }^{3}$ \\ ${ }^{1}$ Program Studi Pendidikan IPS Universitas Negeri Jakarta \\ ${ }^{2}$ Program Studi Pendidikan Teknik Elektronika Universitas Negeri Jakarta \\ ${ }^{3}$ Program Studi Pendidikan IPS Universitas Negeri Jakarta \\ budiaman@unj.ac.id, rusmono@unj.ac.id, nandikurniawan@unj.ac.id
}

\begin{abstract}
This community service program is aimed at empowering teachers to optimize information technologybased social studies learning materials. The partner in this community service activity is the MGMP IPS East Jakarta. The problem faced by partners is the gap in understanding of knowledge about syllabus development, learning materials, and learning media that can be optimized with current developments in information technology. The solution to overcome the problem is by providing assistance from formulating the problem, material orientation, group discussion, and assisting in the preparation of information technology-based social studies material. The method of implementing the activity was begun with a focus group discussion (FGD) between the Chairperson and the Executive Board of the East Jakarta MGMP. The results of the FGDs were implemented in the form of training and mentoring for social studies teachers with material: (1) syllabus development, (2) development of 21st century lesson plans, and (3) information technology-based learning media. The result of this activity was the increase in participants' knowledge and skills in compiling social studies learning materials. The product of the activities in the form of information technology-based learning materials in the form of lesson plans. In addition, workshop participants felt challenged to make information technology-based learning materials more diverse by continuing to realize the idealism of their profession
\end{abstract}

Keywords: Learning Materials, Social , MGMP IPS, Information Technology

\begin{abstract}
Abstrak
Kegiatan pengabdian kepada masyarakat terintegrasi KKN ini bertujuan untuk memberdayakan guru-guru dalam mengoptimalisasikan bahan pembelajaran IPS berbasis teknologi informasi. Mitra dalam kegiatan pengabdian kepada masyarakat ini adalah MGMP IPS Jakarta Timur. Permasalahan yang dihadapi mitra adalah adanya kesenjangan pemahaman pengetahuan tentang pengembangan silabus, bahan pembelajaran, dan media pembelajaran yang dapat dioptimalkan dengan perkembangan teknologi informas saat ini. Solusi untuk mengatasi permasalahan dengan melakukan pendampingan dari merumuskan masalah, orientasi materi, diskusi kelompok, dan pendampingan penyusunan materi IPS berbasis teknologi informasi. Metode pelaksanaan kegiatan dilakukan diawali dengan focus group discussion (FGD) antara Ketua Pelaksana dengan Pengurus MGMP Jakarta Timur. Hasil FGD diimplementasikan dalam bentuk pelatihan dan pendampingan guru-guru IPS dengan materi: (1) pengembangan silabus, (2) pengembangan RPP abad 21, dan (3) media pembelajaran berbasis teknologi informasi. Hasil kegiatan ini adalah meningkatnya pengetahuan peserta dan keterampilan dalam menysusun bahan pembelajaran IPS. Produk hasil kegiatan berupa bahan pembelajaran berbasis teknologi informasi dalam bentuk RPP. Selain itu peserta workshop merasa tertantang untuk membuat bahan pembelajaran berbasis teknologi informasi yang lebih beragam dengan terus mewujudkan idealisme profesinya secara konsisten.
\end{abstract}

Kata Kunci: Bahan Pembelajaran, MGMP IPS, Teknologi Informasi 


\section{PENDAHULUAN}

Tuntutan kompetensi guru abad 21, tidak lagi sekedar mampu mengajar dengan baik melainkan guru pembelajar dan agen perubahan di sekolah dalam proses peningkatan mutu pembelajaran di sekolahnya. Untuk itu, guru membutuhkan pengembangan berbagai kompetensi melalui program pendampingan yang intensif.

Hal yang menjadi tuntutan pengembangan kompetensi guru dewasa ini adalah kemampuan mengembangkan bahan pembelajaran berbasis teknologi informasi. Sehingga dalam melaksanakan proses pembelajaran guru dituntut untuk lebih kreatif dan inovatif dalam melakukan perubahan-perubahan yang sesuai dengan perkembangan teknologi kekinian dalam rangka meningkatkan mutu layanan pendidikan khususnya layanan proses pembelajaran.

Pentingnya bahan pembelajaran dikemukakan Dick \& Carey dalam Uno (2007:1), bahwa bahan ajar adalah seluruh komponen materi pembelajaran dan prosedur atau tahapan kegiatan belajar yang digunakan oleh guru dalam usaha membantu peserta didik mencapai tujuan pembelajaran. Media pembelajaran yang inovatif dapat meningkatkan motivasi siswa dalam proses pembelajaran. Pemanfaatan media pembelajaran juga mendukung keberhasilan menuju kompetensi kognitif dan psikomotor peserta didik yang lebih berkualitas.

Guru mengembangkan pembelajaran dengan menghubungkan teori-teori belajar sebagai aktivitas pembelajaran. Joyce dan Weil dalam
Sani (2013: 98-100) menjelaskan bahwa salah satu model pembelajaran yang berbasis teknologi informasi termasuk dalam kategori model pembelajaran pemrosesan informasi. Dalam konteks komunikasi untuk menyampaikan informasi pada skema, media berfungsi sebagai alat bantu untuk guru dalam mengkomunikasikan pesan seperti yang diskemakan oleh Sanjaya (2008:197).

Berkaitan dengan sistem belajar pemrosesan informasi, kognitivisme yang dikembangkan oleh Gagne dalam Jamaris (2013: 127) memandang bahwa pembelajaran yang terjadi dalam diri individu sebagai kegiatan pemrosesan informasi, yang dianalogikan dengan proses input data dalam komputer. Kegiatan belajar diawali dari input (informasi) yang datang dari lingkungan sekitar individu, diterima laangsung oleh panca indera, kemudian diproses dan disimpan dalam memori, sehingga muncul berbagai bentuk kompetensi hasil belajar. Penggunaan teknologi informasi memungkinkan peserta didik secara langsung berinteraksi dengan bahan ajar yang dipelajari, sehingga berbagai sumber belajar dapat diakses dengan mudah sebagaimana yang dijelaskan dalam Sanjaya (2012:195).

Mencermati kondisi pembelajaran secara umum pada setiap sekolah, dapat diidentifikasi temuan masalah sebagai berikut:

1. Minimnya pemahaman guru tentang penggunaan bahan ajar dan media pembelajaran interaktif sebagai upaya untuk meningkatkan hasil belajar. 
2. Bahan pembelajaran IPS SMP masih kurang variatif baik model bahan ajar maupun media pembelajaran yang digunakan.

3. Ketidaksesuaian bahan ajar dan media pembelajaran dengan kajian materi.

4. Minimnya penggunaan teknologi informasi dalam pembelajaran.

Kemampuan guru dalam upaya memahami pengembangan perangkat, bahan, dan media pembelajaran abad 21 melalui kurikulum 2013 diharapkan dapat memiliki kesamaan, baik dalam kualitas maupun kuantitas, sebagai cerminan kreativitas guru dalam kegiatan mendidik, mengajar, dan melaksanakan peran sebagai fasilitator.

Kegiatan pengabdian ini bertujuan untuk meningkatkan pengetahuan dan keterampilan guru IPS dalam mengembangkan bahan pembelajaran berbasis teknologi informasi. Pengembangan bahan pembelajaran berbasis teknologi informasi merupakan tuntutan sekaligus tantangan para guru untuk terus meningkatkan profesionalisme dalam pembelajaran.

Teknologi informasi dan komunikasi sebagai suatu proses dan produk berkembang sedemikian cepat sehingga mempengaruhi berbagai bidang kehidupan, termasuk dalam pembelajaran (Miarso, 2016; Prawiradilaga, 2013).

Hadirnya teknologi baru sebagai media pembelajaran harus selaras dengan kurikulum 2013. Menurut Arsyad (2014: 203) salah satu impelemntasinya adalah penggunaan internet dalam pembelajaran yang lebih dikenal dengan e-learning. Fungsi pembelajaran e-learning bagi peserta didik adalah mempercepat dan mempermudah penyampaian materi.

Kegiatan ini memberikan manfaat bagi guru dalam menciptakan kreativitas dan pengembangan materi yang variatif, menarik, dan menumbuhkan rasa ingin tahu siswa dalam pembelajaran.

\section{METODE PELAKSANAAN}

Persiapan kegiatan dimulai dengan melakukan sosialisasi dengan pihakpihak terkait, di antaranya Dinas Pendidikan Kota Jakarta Timur, Kepala Sekolah SMPN 172, serta Pengurus MGMP IPS Jakarta Timur. Melalui sosialisasi ini diharapkan semua pihak terkait mendukung sepenuhnya program ini baik secara kelembagaan, materiil maupun moril

Rancangan kurikulum kegiatan optimalisasi bahan pembelajaran IPS berbasis teknologi informasi dapat dilihat pada tabel berikut

Tabel 1. Rancangan Kegiatan

\begin{tabular}{lllc}
\hline No & $\begin{array}{c}\text { Materi } \\
\text { Pembelajaran }\end{array}$ & \multicolumn{1}{c}{ Tujuan } & Alokasi Waktu \\
\hline $\mathbf{1}$ & Tes awal & $\begin{array}{l}\text { Mengetahui kemampuan } \\
\text { awal peserta sebelum } \\
\text { kegiatan }\end{array}$ & 1 jam \\
& & &
\end{tabular}




\begin{tabular}{|c|c|c|c|}
\hline & \multicolumn{3}{|c|}{ Materi Pengembangan Silabus dan RPP abad 21} \\
\hline 2 & $\begin{array}{l}\text { Pengembangan } \\
\text { strategi } \\
\text { penyusunan standar } \\
\text { kurikulum } 2013\end{array}$ & $\begin{array}{l}\text { Peserta mampu mengetahui } \\
\text { makna dan implementasi } \\
\text { kurikulum } 2013\end{array}$ & 2 jam \\
\hline 3 & $\begin{array}{l}\text { Analisis Dokumen } \\
\text { SKL,KI-KD dan } \\
\text { Silabus }\end{array}$ & $\begin{array}{l}\text { Peserta mampu menguasai } \\
\text { teknik pembuatan silabus } \\
\text { IPS yang mengakomodasi } \\
\text { kebutuhan peserta didik }\end{array}$ & 2 jam \\
\hline 4 & $\begin{array}{l}\text { Prinsip-prinsip } \\
\text { pengembangan } \\
\text { silabus IPS }\end{array}$ & $\begin{array}{l}\text { Peserta mampu menguasai } \\
\text { teknis pembuatan silabus } \\
\text { IPS yang mengakomodasi } \\
\text { kebutuhan peserta didik }\end{array}$ & 5 jam \\
\hline 5 & $\begin{array}{l}\text { Praktek } \\
\text { pengembangan } \\
\text { RPP abad } 21\end{array}$ & $\begin{array}{l}\text { Peserta mampu merancang } \\
\text { dan membuat RPP yang } \\
\text { sesuai dengan kebutuhan } \\
\text { pembelajaran di abad } 21\end{array}$ & $12 \mathrm{jam}$ \\
\hline & Materi Media Pe & nbelajaran IPS Berbasis Te & i Informasi \\
\hline 6 & $\begin{array}{l}\text { Pengenalan } \\
\text { lingkungan belajar } \\
\text { abad } 21 \text { di era } \\
\text { revolusi industri } 4.0\end{array}$ & $\begin{array}{lr}\text { Peserta } & \text { mempunyai } \\
\text { informasi dan } & \text { landasan } \\
\text { yang kuat } & \text { dalam } \\
\text { meningkatkan } & \text { kompetensi } \\
\text { menyesuaikan } & \text { diri dengan } \\
\text { dalam } & \text { pesatnya } \\
\text { perkembangan } & \text { teknologi } \\
\text { informasi } & \end{array}$ & 2 jam \\
\hline 7 & $\begin{array}{l}\text { Media } \\
\text { pembelajaran IPS } \\
\text { berbasis teknologi } \\
\text { informasi }\end{array}$ & $\begin{array}{l}\text { Peserta mampu merancang } \\
\text { media pembelajaran IPS } \\
\text { berbasis teknologi } \\
\text { informasi }\end{array}$ & 4 jam \\
\hline 8 & $\begin{array}{l}\text { Simulasi } \\
\text { mengembangkan } \\
\text { media } \\
\text { pembelajaran }\end{array}$ & 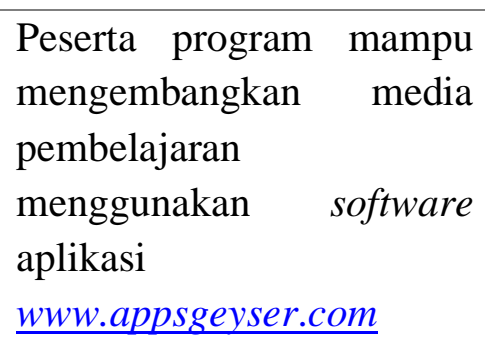 & 6 jam \\
\hline 9 & Tes akhir & $\begin{array}{l}\text { Mengetahui kemampuan } \\
\text { peserta setelah pelaksanaan } \\
\text { kegiatan }\end{array}$ & 1 jam \\
\hline
\end{tabular}




\section{HASIL DAN PEMBAHASAN}

Kegiatan pengabdian masyarakat dilaksanakan pada tanggal $10-17$ September 2019 di MGMP IPS Jakarta Timur yang dilaksanakan di SMPN 172 Jakarta Timur. Program pengabdian kepada masyarakat dibagi dalam beberapa tahapan kegiatan yang meliputi: Focus Group Discussion antara Tim Pelaksana dengan Pengurus MGMP Jakarta Timur, pendampingan guru merancang perangkat pembelajaran abad 21 rumpun mata pelajaran IlmuIlmu Sosial dan Seminar tentang media pembelajaran berbasis Teknologi Informasi.

Metode yang digunakan dalam kegiatan pemberdayaan ini adalah ceramah bervariasi yang disertai penugasan. Peserta workshop diberikan tugas membuat perangkat pembelajaran yang terdiri atas silabus dan RPP berbasis abad 21. Penugasan pembuatan RPP secara lengkap yang terdiri atas bahan pembelajaran, media, metode, dan alat evaluasi. Melalui praktik penyusunan perangkat pembelajaran abad 21 diharapkan dapat meningkatkan proses pembelajaran di kelas sesuai karakteristik dan tantangan abad 21.

Pada tahap awal pelatihan dilakukan tes awal untuk memetakan pengetahuan peserta mengenai materi yang akan diberikan. Dari hasil tes awal di ketahui bahwa pemahaman guru guru IPS dalam konsep pembelajaran yang berbasis teknologi informasi baik tugas guru maupun pemahaman media pembelajarannya masih tergolong rendah. Sehingga pembekalan mengenai konsep pembelajaran berbasis teknologi informasi yang sesuai dengan implementasi kurkulum 2013 harus di berikan secara komprehensif. Hal ini perlu diberikan agar menjadi landasan dalam penyusunan silabus dan RPP yang disesuaikan dengan tujuan pembelajaran.

Pada tanggal 10 September 2019, antara jam $10.00-12.00$ WIB, Dr. Budiaman, M.Si selaku narasumber memberikan materi Pengembangan Silabus dan RPP abad 21. Untuk mengembangkan bahan pembelajaran yang sesuai dengan tuntutan perkembangan teknologi informasi abad 21 direncanakan diawali dengan menganalisis Kompetensi Dasar hingga menyusun RPP yang terintegrasi dengan teknologi informasi dan bahan belajar yang nantinya dapat dimanfaatkan di kelas.

Materi pertama diawali dengan penyamaan persepsi mengenai standar kurikulum 2013. Pada awalnya terdapat pro dan kontra di peserta pelatihan mengenai kelebihan dan kekurangan kurikulum 2013 dibandingkan KTSP. Namun pada akhirnya setelah banyak diskusi disepakati bahwa kurikulum yang ada sejatinya dibuat harus relevan dengan kehidupan sehari hari yang terus berkembang dan guru harus meningkatkan pengetahuannya.

Pada sesi 2, antara jam 13.00 15.00, diadakan pendampingan guru dalam pembuatan RPP IPS Kelas VII, VIII, dan IX. Peserta yang berjumlah 22 guru dibagi menjadi 3 kelompok kelas, masing-masing kelompok berjumlah 7 guru dan 1 kelompok ada yang 
berjumlah 8 guru. Ketua MGMP IPS meminta kelompok 1 untuk membuat RPP Kelas VII semester gasal, kelompok 2 diminta untuk membuat RPP Kelas VIII semester gasal, dan kelompok 3 membuat RPP Kelas IX semester gasal. Tugas ini dikerjakan sampai jam 15.00,

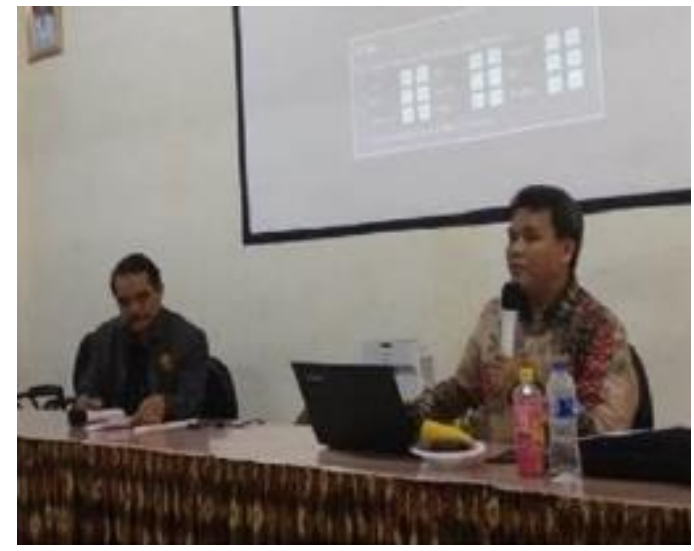

Gambar 1. Dr. Budiaman, M.Si tengah memberikan materi Pengembangan Silabus

Pada tanggal 17 September 2019, dilakukan program simulasi tentang Media Pembelajaran IPS Berbasis Teknologi Informasi. Narasumber kegiatan simulasi ini adalah Dr. Ir. Rusmono, M.Pd. Materi disampaikan dengan ceramah bervariasi, contoh konkrit, dan simulasi melalui aplikasi komputer.

Kegiatan praktek ini didampingi dan dikoordinasi oleh Ketua MGMP IPS Jakarta Timur agar lebih terarah, terkoordinasi dan memudahkan laporan dan diteruskan menjadi pekerjaan rumah masing-masing kelompok. Meskipun para guru sibuk dengan kegiatan di sekolah masing-masing, tetapi para guru masih dapat berkomunikasi dalam mengerjakan tugas melalui media sosial dan email.

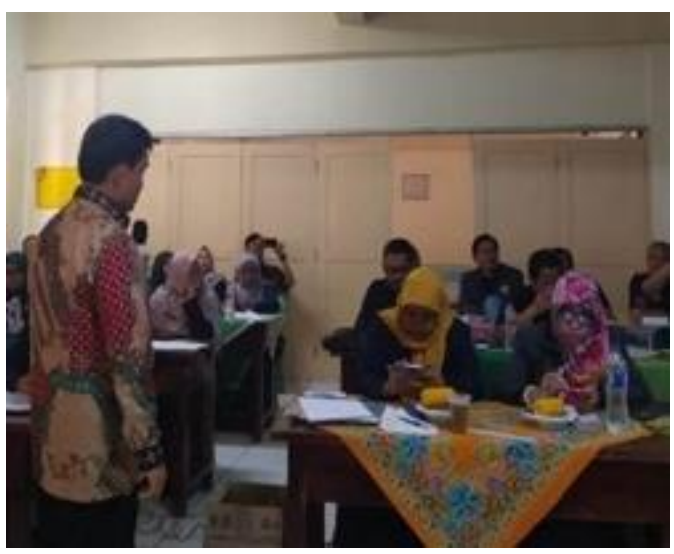

serta evaluasinya. Peserta dibagi kedalam beberapa kelompok dengan pembuatan RPP dengan jenjang yang berbeda agar hasilnya dapat lebih mewakili keseluruhan materi IPS. Peserta diberikan keleluasaan dan waktu cukup panjang untuk mengeksplorasi , berinovasi serta mewadahi berbagai ide kreatif dalam pembuatan RPP tersebut. Hasil praktek kerja tersebut dikumpulkan secara kolektif pada Ketua MGMP Jakarta Timur yang selanjutnya diteruskan pada Ketua Pelaksana PkM. 

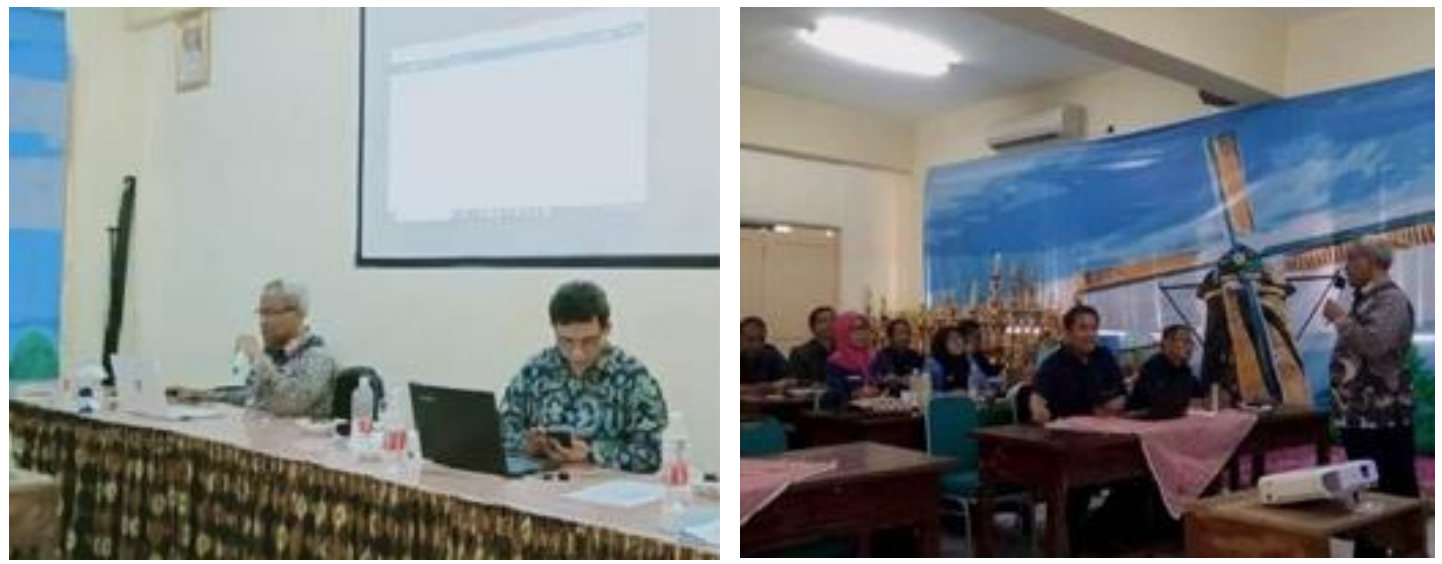

Gambar 2. Dr. Ir. Rusmono memberikan materi Media Pembelajaran Berbasis IT

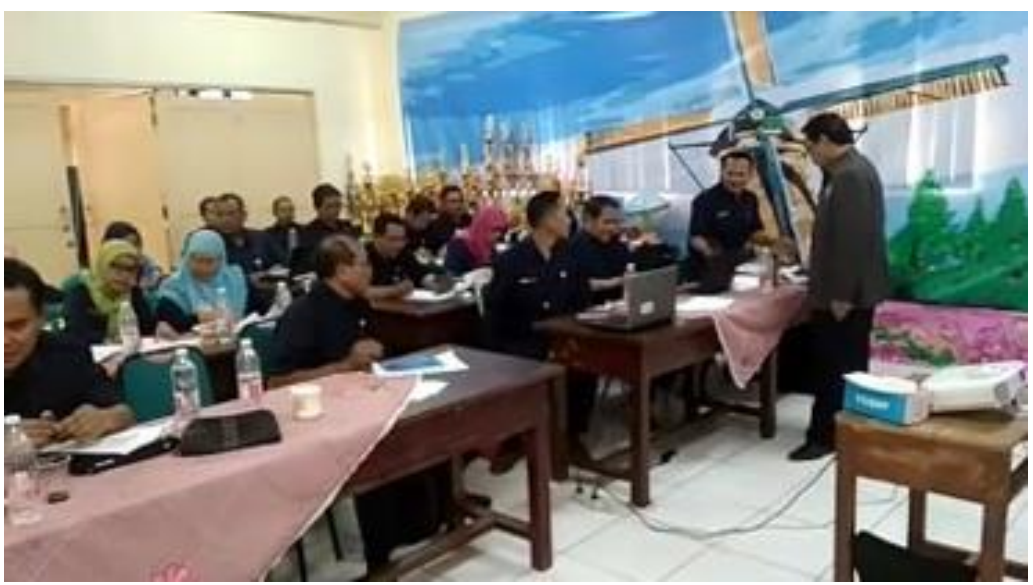

Gambar 3. Kegiatan Kerja Kelompok Peserta Workshop di dampingi Ketua MGMP Pendidikan IPS

Materi yang diberikan pada pekan kedua kegiatan adalah tentang pengembangan media pembelajaran berbasis teknologi informasi. Sesuai dengan diskusi materi sebelumnya bahwa kurikulum 2013 lebih menekankan kompetensi siswa secara menyeluruh dan utuh, maka pengembangan berpusat bagaimana menumbuhkan keaktifan dan kompetensi dasar yang dimiliki siswa mengikuti perkembangan zaman yang dikenal sebagai era revolusi industri 4.0. Media pembelajaran memiliki peran strategis dalam peran tersebut. Media pembelajaran bukan lagi menjadi sarana penunjang tetapi menjadi agen perubahan strategi pembelajaran konvensional.

Materi media pembelajaran berbasis teknologi informasi diberikan dalam langkah langkah operasional dalam berbagai model, teknis pembuatan substansi, penyusunan peta kompetensi hingga pengembangan tes formatif untuk tujuan pembelajaran. Materi dilengkapi dengan simulasi dan praktek mengembangkan media pembelajaran berbasis teknologi informasi menggunakan software aplikasi www.appsgeyser.com

Metode yang digunakan dalam kegiatan pelatihan ini adalah presentasi, ceramah, diskusi, simulasi dan 
demonstrasi yang disertai penugasan. Bahan ajar berupa RPP yang dibuat sendiri oleh guru sangat bermanfaat untuk membantu praktik kegiatan pembelajaran di kelas. Dengan bahan ajar yang sudah tersusun sesuai pemikiran guru dan tetap berada pada jalur kurikulum 2013, maka secara garis besar guru sudah melakukan efisiensi waktu dan tenaga. Guru tidak perlu bicara panjang lebar dan bingung mencari rencana pembelajaran yang akan digunakan, karena semua yang menjadi acuan kegiatan pembelajaran sudah tercantum dalam kumpulan bahan ajar yang dibukukan.

Tugas dan praktik yang diberikan oleh narasumber ternyata sangat membangkitkan motivasi peserta pelatihan untuk dapat mengembangkan wawasan keilmuan dan pengetahuan menjadi lebih baik, serta meningkatkan profesionalismenya sebagai guru di SMP. Sikap yang termotivasi tersebut tampak dari antusias peserta dalam melaksanakan tugas-tugas pelatihan dengan sungguh-sungguh. Kesungguhan peserta workshop menunjukkan bahwa para guru benar-benar ingin membuktikan mereka adalah guru yang baik, serta memiliki kompetensi akademik yang baik sebagai evaluator sesuai dengan standar penilaian dalam kurikulum 2013.

Pelaksanaan pelatihan optimalisasi bahan pembelajaran berbasis teknologi informasi diakhiri dengan pelaksanaan tes akhir. Pada saat pelaksanaan tes awal, hasil rata-rata kemampuan peserta adalah 6.13 sedangkan pada tes akhir nilai rata-rata yang diperoleh adalah 7,43. Hasil nilai tes tersebut secara detail dimuat dalam lampiran. Peningkatan pengetahuan peserta memang tidak terlalu besar besar, mengingat substansi soal tes lebih banyak mengenai bagaimana merencanakan bahan pembelajaran secara filosofis. Namun perubahan pola pikir, bertambahnya wawasan serta meningkatnya keterampilan guru untuk mencoba mengembangkan bahan pembelajaran berbasis teknologi informasi yang bervariatif semakin menunjukkan peningkatan yang sangat berarti. Dukungan sarana yang cukup memadai dengan ketersediaan laptop dan LCD proyektor dari SMPN 172 sangat membantu kelancaran kegiatan workshop, sehingga tujuan kegiatan dapat langsung menuju sasaran sesuai harapan. 


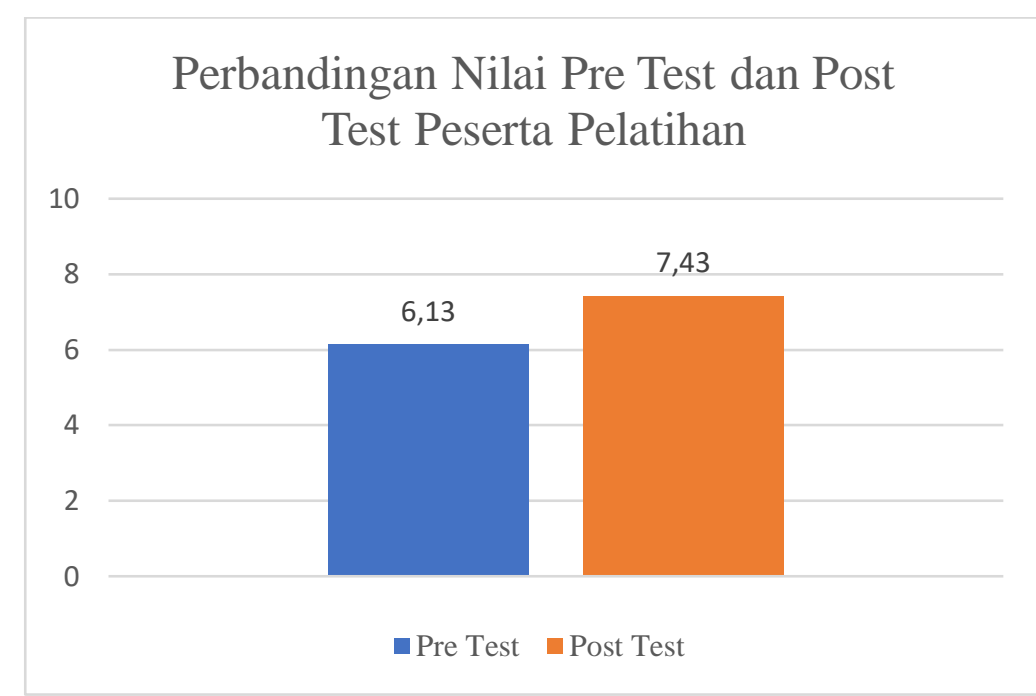

\section{Gambar 4. Grafik Perbandingan Nilai Pre Test dan Post Test Peserta Pelatihan}

\section{PENUTUP}

Di era digital seperti saat ini kebutuhan untuk menggunakan media pembelajaran berbasis teknologi informasi dan komunikasi terus meningkat. Salah satu faktor yang mempengaruhi kualitas pembelajaran adalah bahan pembelajaran yang dikemas semakin variatif berbasis teknologi informasi.

Berdasarkan hasil kegiatan pelatihan penyusunan bahan pembelajaran berbasis teknologi informasi dapat disimpulkan bahwa pemahaman guru-guru IPS terhadap pembuatan bahan ajar yang sesuai dengan perkembangan teknologi informasi sebagai kegiatan pengembangan kompetensi kinerja guru masih harus ditingkatkan. Guru harus terus berupaya meningkatkan keterampilan dalam teknologi informasi untuk pembelajaran, baik secara mandiri maupun terorganisir melalui kegiatan MGMP.

Bagi segenap pimpinan dan guruguru IPS MGMP Jakarta Timur meskipun kegiatan pendampingan terlaksana dengan baik, tetapi tidak luput dari kekurangan. Kekurangan dari kegiatan ini terletak pada waktu yang sangat terbatas dan kehadiran peserta yang kurang optimal.

Bagi Pengawas dan Dinas Pendidikan Kotamadya Jakarta Timur, diharapkan dapat terus melakukan pembinaan terhadap guru dalam rangka meningkatkan kompetensinya, baik kompetensi profesional, kompetensi pedagogik, kompetensi sosial, dan kompetensi kepribadian. Sinergitas peningkatan kualitas guru juga dapat dikembangkan melalui jalinan kerja sama antara Dinas Pendidikan dengan Perguruan Tinggi.

\section{DAFTAR PUSTAKA}

Arsyad, Azhar. 2014. Media Pembelajaran. Jakarta: Rajawali Pers.

Jamaris, Martini. 2013. Orientasi Baru Dalam Psikologi Pendidikan: Ghalia Indonesia. 
Miarso, Yusufhadi, 2016. Menyemai Benih Teknologi Pendidikan, Edisi Kedua. Jakarta: Prenadamedia Group.

Prawiladilaga, Dewi Salma; Diana Ariani, Hilman Handoko, 2013. Mozaik Teknologi Pendidikan elearning. Kencana.

Sani, Ridwan, Abdulah. 2013. Inovasi Pembelajaran: Bumi Aksara.

Sanjaya, Wina. 2008. Perencanaan dan Desaian Sistem Pembelajaran. Jakarta: Prenada Media Group.
2012. Media Komunikasi Pembelajaran: Prenada Media Group.

Suherman, Eman, 2008. Desain Pembelajaran Kewirausahaan. Alfabeta.

Suparman, Atwi, 2014. Desain Instruksional Modern. Erlangga

Uno, Hamzah B, 2016. Perencanaan Pembelajaran: Bumi Aksara 